\title{
EVALUASI SETTLEMENT MENGGUNAKAN SURCHARGE PRELOADING DENGAN PVD PADA PROYEK DI BANDUNG SELATAN
}

\author{
Michael Christopher Yapriadi ${ }^{1}$, Inda Sumarli ${ }^{2}$, dan Ali Iskandar ${ }^{3}$ \\ ${ }^{1}$ Program Studi Sarjana Teknik Sipil, Universitas Tarumanagara, Jl. Letjen S. Parman No.1 Jakarta \\ michael.325160076@stu.untar.ac.id \\ ${ }^{2}$ Program Studi Sarjana Teknik Sipil, Universitas Tarumanagara, Jl. Letjen S. Parman No.1 Jakarta \\ indasumarli@gmail.com \\ ${ }^{3}$ Program Studi Sarjana Teknik Sipil, Universitas Tarumanagara, Jl. Letjen S. Parman No.1 Jakarta \\ ali.iskandar1999@gmail.com
}

\begin{abstract}
The development in Indonesia continues to grow. Hence, the feasible land for construction is drastically decreased. However, some projects must be constructed on that kind of land. One solution to solve this problem is by using a soil improvement. A project in Bandung Selatan chose to apply Surcharge Preloading with PVD soil improvement method. This project used a combination of 9,2 metres surcharge preload and a 28 metres depth PVD, with triangular formation and 1,2 metres spacing. The soil improvement was finished after 548 days. This analysis aims to evaluate the settlement from the soil improvement result, which is 1,297 metres. This analysis uses a finite difference method program. The excess pore water pressure from the analysis result is $0,229 \mathrm{~T} / \mathrm{m} 2 \mathrm{on}$ the 548th day. Therefore, these soil layers have possibilities to settle again in future. The 90\% degree of consolidation settlement for this soil layers is 2,31 metres, which will be reached on the 813,4th days. It is suspected that there are some mistakes either during the soil improvement designing or the soil improvement process.
\end{abstract}

Keywords: PVD; surcharge preloading; consolidation settlement; finite difference method

\begin{abstract}
ABSTRAK
Pembangunan di Indonesia terus berkembang. Akibatnya jumlah tanah yang baik untuk proyek konstruksi semakin menipis. Kendati demikian, ada kalanya suatu proyek harus dilaksanakan di lokasi tersebut. Salah satu solusi yang dapat ditempuh adalah dengan melakukan perbaikan tanah. Sebuah proyek di Bandung Selatan melakukan perbaikan tanah dengan metode Surcharge Preloading dengan PVD. Proyek ini menggunakan kombinasi antara timbunan setinggi 9,2 meter dan PVD sedalam 28 meter, dengan formasi segitiga yang dipasang dengan jarak antar PVD 1,2 meter. Perbaikan tanah dilakukan selama 548 hari. Analisis ini bertujuan melakukan evaluasi terhadap kurang maksimalnya penurunan di lapangan yang hanya mencapai 1,297 meter. Analisis dilakukan dengan bantuan program beda hingga. Berdasarkan hasil analisis, besarnya excess pore water pressure pada hari ke-548 adalah $0,229 \mathrm{~T} / \mathrm{m}^{2}$, , sehingga lapisan tanah tersebut masih memiliki potensi untuk mengalami penurunan. Adapun penurunan konsolidasi $90 \%$ yang dapat terjadi sebesar 2,31 meter pada hari ke-813,4. Diduga terdapat kesalahan baik dalam perhitungan perencanaan awal ataupun saat pelaksanaan di lapangan.
\end{abstract}

Kata kunci: PVD; surcharge preloading; penurunan konsolidasi; program beda hingga

\section{PENDAHULUAN}

Pertumbuhan kota-kota di dunia semakin cepat. Ini mengakibatkan semakin meningkatkan kebutuhan akan bangunan-bangunan untuk mendukung pertumbuhan suatu kota. Padahal, lahan di kota-kota besar seperti Jakarta sudah semakin sedikit. Seringkali, yang tersisa hanyalah lahan yang sebenarnya tidak feasible. Kendati demikian, tentu saja ada berbagai alasan yang menyebabkan bangunan tersebut harus tetap didirikan di lokasi tersebut, misalnya lokasi yang strategis, tidak ada lahan lain, fungsi bangunan yang esensial dan harus ada di daerah tersebut, dan lain sebagainya. Oleh karena itu, salah satu cara yang ditawarkan untuk mengatasi lahan yang sebenarnya kurang layak untuk didirikan bangunan tersebut adalah dengan melakukan perbaikan tanah. 
Perbaikan tanah, atau juga dikenal sebagai soil improvement atau ground improvement merupakan suatu cara untuk mengubah karakteristik tanah menjadi lebih baik sehingga mampu mendukung struktur yang akan didirikan di atasnya. Ada berbagai metode yang bisa ditempuh untuk melakukan perbaikan tanah, misalnya pemadatan tanah, preloading, grouting, penggunaan material geotextile, dan sebagainya. Pemilihan metode tersebut harus dipertimbangkan dengan matang, agar tujuan yang diinginkan dapat tercapai dan dampak negatif yang dihasilkan juga dapat diminimalisir.

Pada penelitian ini, proyek yang ditinjau berlokasi di daerah Bandung Selatan. Data tanah yang ada menunjukkan bahwa tanah di daerah tersebut memiliki jenis tanah lempung yang sangat lunak hingga kedalaman 20 meter. Untuk mendukung pembangunan di atas tanah jenis tersebut, dilakukan perbaikan tanah. Salah satu cara yang ditempuh dalam penelitian ini adalah perbaikan tanah dengan menggunakan metode surcharge preloading yang dikombinasikan dengan PVD (Prefabricated Vertical Drain). Untuk mendapatkan hasil sesuai dengan yang diinginkan, pelaksanaan perbaikan tanah perlu dilakukan dengan cermat. Sayangnya, hasil dari proses perbaikan tanah dengan metode surcharge preloading dengan PVD pada proyek ini belum sepenuhnya maksimal.

Berdasarkan hal-hal yang telah diuraikan di atas, rumusan masalah dalam penelitian ini dapat diuraikan sebagai berikut.

1. Berapa besar penurunan tanah yang terjadi jika dipadatkan menggunakan metode surcharge preloading dengan PVD?

2. Berapa besar excess pore water pressure pada yang telah diperbaiki menggunakan metode surcharge preloading dengan PVD?

3. Apa penyebab hasil perbaikan tanah dengan metode surcharge preloading dengan PVD pada proyek ini kurang maksimal?

Berdasarkan rumusan masalah yang ada, tujuan dari penelitian ini adalah sebagai berikut.

1. Mengetahui besar penurunan tanah yang terjadi setelah pemadatan menggunakan metode surcharge preloading dengan PVD.

2. Mengetahui besar excess pore water pressure pada tanah yang telah diperbaiki menggunakan metode surcharge preloading dengan PVD.

3. Mengetahui penyebab hasil perbaikan tanah dengan metode surcharge preloading dengan PVD pada proyek ini kurang maksimal.

\section{Penurunan tanah}

Penurunan tanah atau settlement merupakan peristiwa berkurangnya ketebalan suatu lapisan tanah akibat memadatnya partikel-partikel tanah. Penurunan ini diakibatkan oleh adanya beban yang bekerja pada suatu lapisan tanah, dan menyebabkan terjadinya tegangan tanah. Peristiwa penurunan ini merupakan suatu hal yang tidak dapat dihindari dan terjadi sepanjang masa (Budhu, 2015). Menurut Das (2013), secara umum penurunan tanah dapat dibedakan menjadi tiga, yaitu penurunan elastis, penurunan konsolidasi primer, dan penurunan konsolidasi sekunder. Penurunan tanah elastis atau elastic settlement, merupakan penurunan tanah yang terjadi secara langsung setelah tanah menerima beban luar. Janbu et al. (dalam Das, 2014) mengemukakan formula untuk menghitung besarnya penurunan elastis $\left(\mathrm{S}_{\mathrm{e}}\right)$ seperti pada persamaan:

$$
S_{e}=A_{1} A_{2} \frac{q_{o} B}{E_{S}}
$$

dengan $\mathrm{q}_{\mathrm{o}}=$ tegangan pada dasar beban, $\mathrm{B}=$ lebar beban, $\mathrm{E}_{\mathrm{s}}=$ modulus elastisitas tanah, $\mathrm{A}_{1}$ dan $\mathrm{A}_{2}$ berasal dari Gambar 1 . 


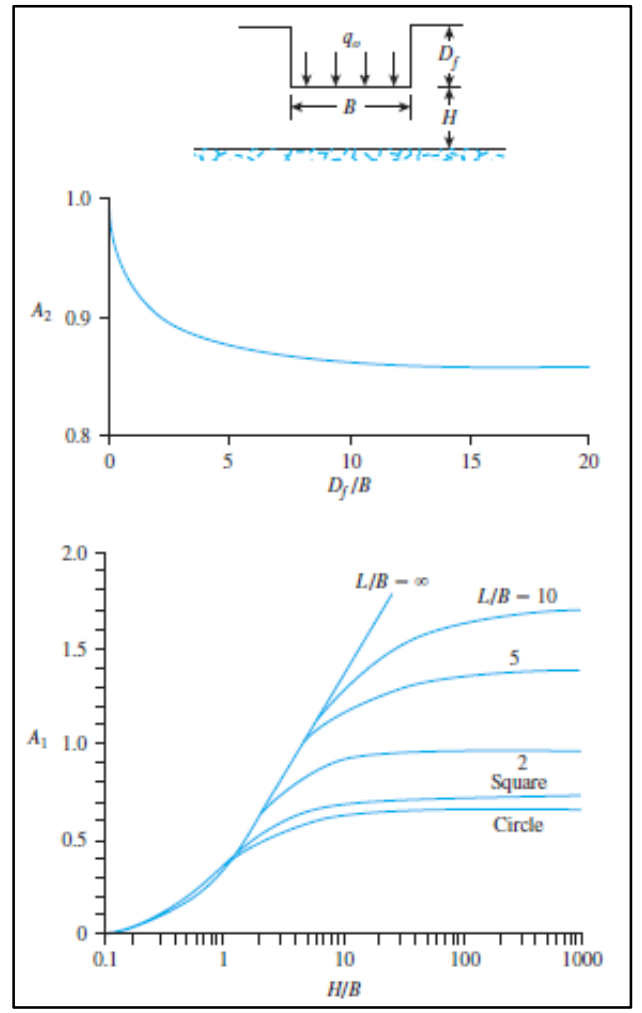

Gambar 1. Nilai $A_{1}$ dan $A_{2}$ untuk penurunan elastis tanah (Sumber: Das, 2014)

Konsolidasi merupakan proses disipasi kelebihan air pori pada material tanah yang disebabkan oleh beban yang diberikan pada lapisan tanah (Han, 2015). Konsolidasi menyebabkan terjadinya penurunan tanah akibat terjadinya pemampatan butiran tanah. Konsolidasi lebih besar terjadi pada tanah lunak, karena pori-pori pada tanah lunak lebih banyak. Hal ini terjadi akibat air yang terdisipasi keluar melalui pori-pori yang ada pada tanah. Konsolidasi dibagi menjadi konsolidasi primer dan konsolidasi sekunder. Seluruh proses disipasi kelebihan air yang terjadi disebut konsolidasi primer. Konsolidasi primer selesai ketika seluruh kelebihan air terdisipasi sepenuhnya. Pada tanah over consolidated, besarnya konsolidasi primer $\left(\mathrm{S}_{\mathrm{c}}\right)$ dapat dihitung sebagai berikut.

$$
S_{C}=\frac{C_{S} H}{1+e_{o}} \log \left(\frac{P_{o}^{\prime}+\Delta P^{\prime}}{P_{o}^{\prime}}\right)
$$

Sedangkan untuk tanah normally consolidated dapat dihitung dengan persamaan berikut.

$$
S_{c}=\frac{C_{S} H}{1+e_{o}} \log \frac{P_{c}^{\prime}}{P_{o}^{\prime}}+\frac{C_{C} H}{1+e_{0}} \log \left(\frac{P_{o}^{\prime}+\Delta P^{\prime}}{P_{c}^{\prime}}\right)
$$

dengan $\mathrm{H}=$ tebal lapisan tanah yang ditinjau, $\mathrm{e}_{\mathrm{o}}=$ angka pori pada awal konsolidasi, $\mathrm{p}_{\mathrm{o}}^{\prime}=$ tegangan awal tanah, $\Delta \mathrm{P}$ = tegangan tambahan pada tanah, $\mathrm{p}_{\mathrm{c}}^{\prime}=$ tegangan prakonsolidasi, $\mathrm{C}_{\mathrm{c}}=$ koefisien kompresibilitas, dan $\mathrm{C}_{\mathrm{s}}=$ swell index.

Beberapa tanah, tetap mengalami penurunan setelah konsolidasi primernya selesai. Penurunan ini terjadi akibat adanya penyesuaian terhadap partikel-partikel yang ada di dalam tanah. Penurunan yang terjadi setelah selesainya konsolidasi primer disebut konsolidasi sekunder (Das, 2019). Sulit untuk menentukan perbedaan antara konsolidasi primer dan konsolidasi sekunder. Karena konsolidasi sekunder terjadi bersamaan dengan konsolidasi primer, dan juga merupakan bagian dari konsolidasi primer. Konsolidasi sekunder $\left(\mathrm{S}_{\mathrm{s}}\right)$ dapat dinyatakan dalam persamaan berikut.

$$
S_{S}=C_{\propto}^{\prime} H \log \left(\frac{t_{2}}{t_{1}}\right)
$$

dengan $\mathrm{C}_{\alpha}^{\prime}=$ koefisien konsolidasi sekunder terkoreksi, serta $\mathrm{t}_{1}$ dan $\mathrm{t}_{2}$ adalah waktu.

Berdasarkan empat persamaan di atas, besarnya penurunan total suatu lapisan tanah dapat dihitung dengan persamaan berikut.

$$
S_{T}=S_{C}+S_{S}+S_{e}
$$


Penurunan elastis terjadi langsung ketika beban diberikan pada permukaan tanah. Sebaliknya, konsolidasi memerlukan waktu untuk terjadi dan berhenti. Lamanya waktu konsolidasi dipengaruhi oleh jenis tanah dan tebal lapisan tanah. Lamanya waktu konsolidasi dapat dihitung dengan persamaan yang dikemukakan Das (2013) sebagai berikut.

$$
T_{v}=\frac{C_{v} t}{H_{d r^{2}}}
$$

di mana $\mathrm{T}_{\mathrm{v}}=$ faktor waktu konsolidasi, $\mathrm{c}_{\mathrm{v}}=$ koefisien konsolidasi horizontal, $\mathrm{t}=$ waktu konsolidasi, dan $\mathrm{H}_{\mathrm{dr}}=$ tebal lapisan. Pada drainase radial seperti PVD, $\mathrm{T}_{\mathrm{v}}$ menjadi $\mathrm{T}_{\mathrm{r}}, \mathrm{c}_{\mathrm{v}}$ menjadi $\mathrm{c}_{\mathrm{h}}$. Sedangkan nilai $\mathrm{H}_{\mathrm{dr}}$ berubah menjadi equivalent influence diameter PVD (Das, 2014). Adapun nilai $\mathrm{T}_{\mathrm{r}}$ pada drainase radial dapat dihitung dengan persamaan berikut.

$$
U_{r}=1-\exp \left(\frac{-8 T_{r}}{m}\right)
$$

dengan $\mathrm{U}_{\mathrm{r}}$ adalah derajat konsolidasi radial, $\mathrm{m}$ ditentukan dalam persamaan berikut.

$$
m=\left(\frac{n^{2}}{n^{2}-1}\right) \ln n-\frac{3 n^{2}-1}{4 n^{2}}
$$

di mana $\mathrm{n}$ adalah rasio antara equivalent influence diameter PVD dengan diameter ekivalen PVD seperti dalam persamaan berikut.

$$
n=\frac{d_{e}}{d_{c}}
$$

dengan $\mathrm{d}_{\mathrm{e}}=$ equivalent influence diameter of PVD dan $\mathrm{d}_{\mathrm{c}}=$ diameter ekivalen PVD.

\section{Excess pore water pressure}

Excess pore water pressure merupakan tegangan air yang timbul akibat tanah diberi beban tambahan. Ketika tidak ada beban luar, tegangan tanah akibat berat sendiri tanah dengan tegangan air dalam tanah adalah seimbang. Nilai dari excess pore water pressure ini sama besar dengan besarnya beban luar yang diberikan kepada tanah, dengan arah yang berlawanan dengan arah beban. Seiring dengan waktu, air akan keluar dari pori-pori tanah dan menyebabkan tekanan yang arahnya berlawanan dengan beban berkurang hingga pada suatu saat mencapai titik keseimbangan, yaitu sesuai berat tanah dan berat beban luar (Kaliakin, 2017).

\section{Teori Boussinesq}

Suatu beban yang diletakkan di atas permukaan suatu lapisan tanah, akan memberikan dampak kepada lapisanlapisan tanah yang ada di bawahnya. Beban tersebut akan memberikan tegangan pada lapisan di bawahnya. Besarnya tegangan yang dirasakan oleh setiap lapisan akan berbeda, di mana semakin jauh dari titik beban, nilainya akan semakin mengecil. Salah satu teori yang umum digunakan dalam menghitung tegangan tanah ini adalah Teori Boussinesq. Boussinesq (1883) mengemukakan persamaan untuk mencari nilai tegangan pada tanah $\left(\Delta \sigma_{\mathrm{z}}\right)$ akibat beban timbunan seperti persamaan berikut.

$$
\Delta \sigma_{z}=\frac{q_{o}}{\pi}\left[\left(\frac{B_{1}+B_{2}}{B_{2}}\right)\left(\alpha_{1}+\alpha_{2}\right)-\frac{B_{1}}{B_{2}}\left(\alpha_{2}\right)\right]
$$

di mana $\alpha_{1}$ dan $\alpha_{2}$ seperti pada persamaan berikut.

$$
\begin{gathered}
\alpha_{1}=\tan ^{-1}\left(\frac{B_{1}+B_{2}}{z}\right)-\tan ^{-1}\left(\frac{B_{1}}{z}\right) \\
\alpha_{2}=\tan ^{-1}\left(\frac{B_{1}}{z}\right)
\end{gathered}
$$

dan nilai $\mathrm{q}_{\mathrm{o}}, \mathrm{B}_{1}$, dan $\mathrm{B}_{2}$ seperti pada Gambar 2 . 


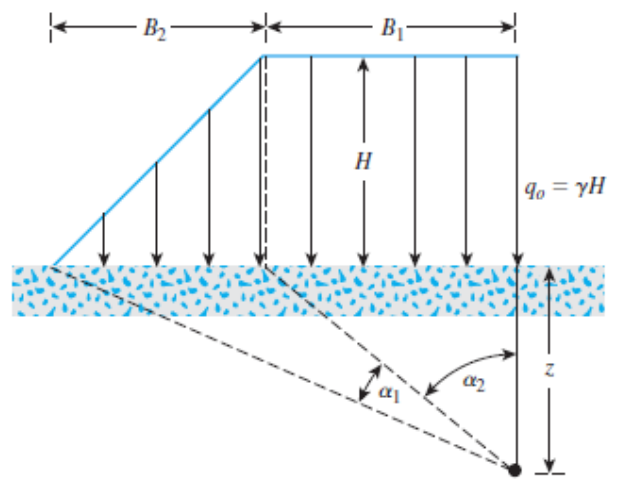

Gambar 2. Tegangan akibat beban merata dengan Metode Boussinesq (Sumber: Das, 2013)

\section{Surcharge preloading dengan PVD}

Tidak semua tanah pada suatu lokasi sesuai dengan kebutuhan bangunan yang akan berdiri di atasnya. Ada kalanya, suatu proyek harus dilakukan pada lokasi dengan kondisi tanah yang tidak memadai. Salah satu metode yang dapat digunakan untuk perbaikan tanah adalah prakonsolidasi atau preconsolidation. Konsep dasar dari prakonsolidasi ialah konsolidasi itu sendiri, yaitu proses keluarnya air dari dalam pori-pori tanah. Tujuan utamanya ialah mengonsolidasikan tanah sehingga penurunan tanah di masa depan menjadi lebih sedikit. Akibat tercapainya konsolidasi ini, tanah yang tadinya lunak menjadi lebih layak padat dan memungkinkan untuk mendirikan bangunan di atasnya. Cara paling sederhana yang dapat ditempuh untuk melakukan prakonsolidasi adalah dengan memberikan beban di atas lapisan tanah yang ingin dikonsolidasikan. Metode ini umumnya disebut surcharge preloading. Cara ini umumnya memakan waktu yang cukup lama, sehingga muncullah kombinasi surcharge preloading dengan PVD yang mampu mengonsolidasi tanah dalam waktu relatif lebih cepat. Tanpa adanya PVD, aliran air keluar dari tanah akan menuju ke atas sesuai ketebalan lapisan tanah seperti pada Gambar 3. Adanya PVD akan menyebabkan konsolidasi menjadi lebih cepat, karena kandungan air yang berada dalam radius influence point PVD bergerak secara horizontal ke arah PVD untuk keluar melalui PVD, sehingga jarak yang ditempuh untuk keluar lebih pendek seperti pada Gambar 4.

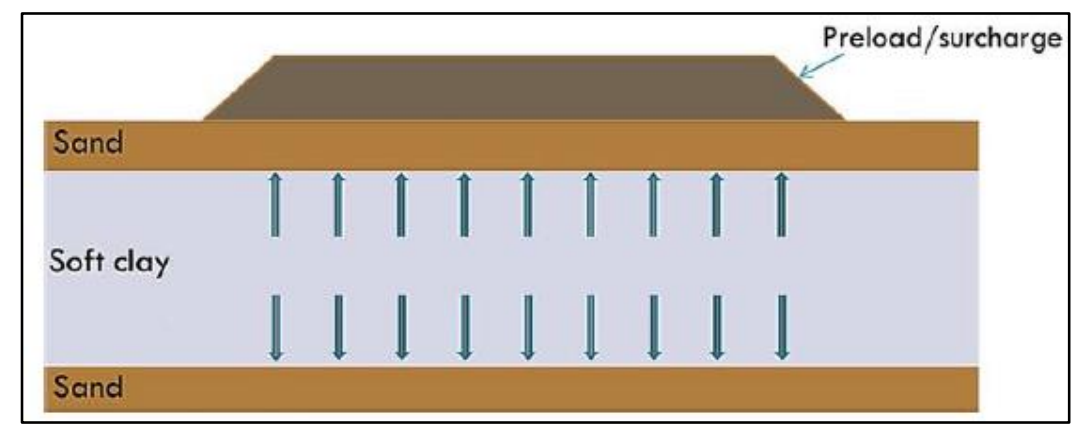

Gambar 3. Surcharge preloading tanpa PVD (Sumber: Sakleshpur dkk., 2018)

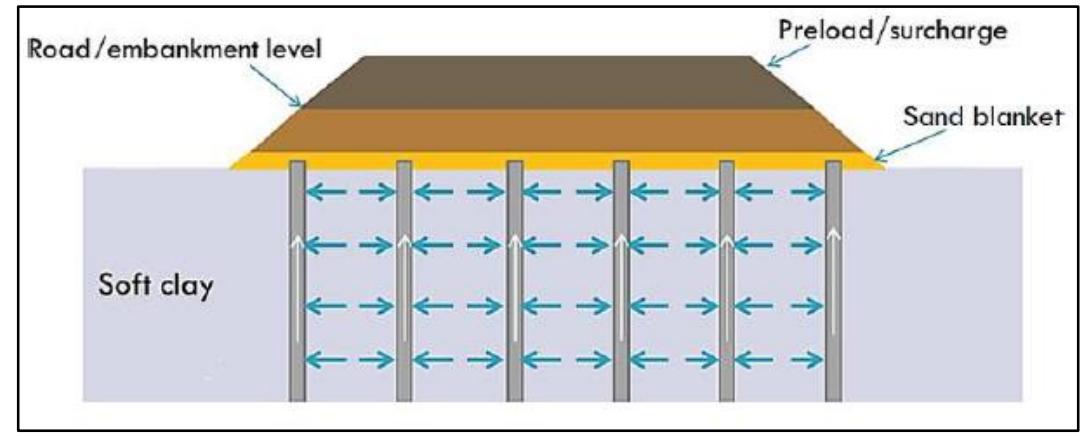

Gambar 4. Surcharge preloading dengan PVD (Sumber: Sakleshpur dkk., 2018) 
PVD telah terbukti dapat mempercepat waktu konsolidasi suatu lapisan tanah. Dalam peneilitian Gunawan et al. (2020), suatu lapisan tanah setebal $21 \mathrm{~m}$ yang diberi beban timbunan setinggi $5 \mathrm{~m}$ akan mencapai derajat konsolidasi $90 \%$ dalam waktu 68,54 bulan. Sementara itu dengan bantuan PVD, derajat konsolidasi $90 \%$ dicapai hanya dalam 9,68 bulan. Studi kasus lain yang berlokasi juga di Bandung Selatan oleh Wilson dan Susilo (2018), menyimpulkan bahwa PVD membuat konsolidasi lapisan tanah 30 meter yang awalnya sebesar 0,2602 meter menjadi 0,2132 meter.

Han (2015) menyatakan bahwa influence equivalent diameter $\left(\mathrm{d}_{\mathrm{e}}\right)$ suatu PVD dinyatakan seperti persamaan berikut.

Untuk PVD dengan pola persegi:

$$
\mathrm{d}_{\mathrm{e}}=1,13 \mathrm{~s}
$$

Untuk PVD dengan pola segitiga:

$$
\mathrm{d}_{\mathrm{e}}=1,06 \mathrm{~s}
$$

di mana $\mathrm{s}=$ jarak spasi antar PVD.

Prativi et al. (2019), dalam penelitiannya menyatakan bahwa semakin dekat jarak antar PVD, maka semakin cepat pula suatu tanah untuk mencapai derajat konsolidasi tertentu. Akan tetapi perlu diperhatikan bahwa pada saat instalasi PVD menggunakan mandrel, tanah di sekitar PVD menjadi terganggu dan menyebabkan terjadinya smearing effect, seperti ditunjukkan pada Gambar 5. Smearing effect menyebabkan timbulnya smearing zone, yaitu zona yang terganggu akibat pemasangan PVD menggunakan mandrel. Pada zona ini, konduktivitas hidrolik suatu tanah mengalami penurunan. Konduktivitas hidrolik tanah undistrubed lebih besar 1,03 sampai 1,25 kali dibandingkan dengan tanah pada daerah smear zone (Tran-Nguyen dan Edil, 2019).

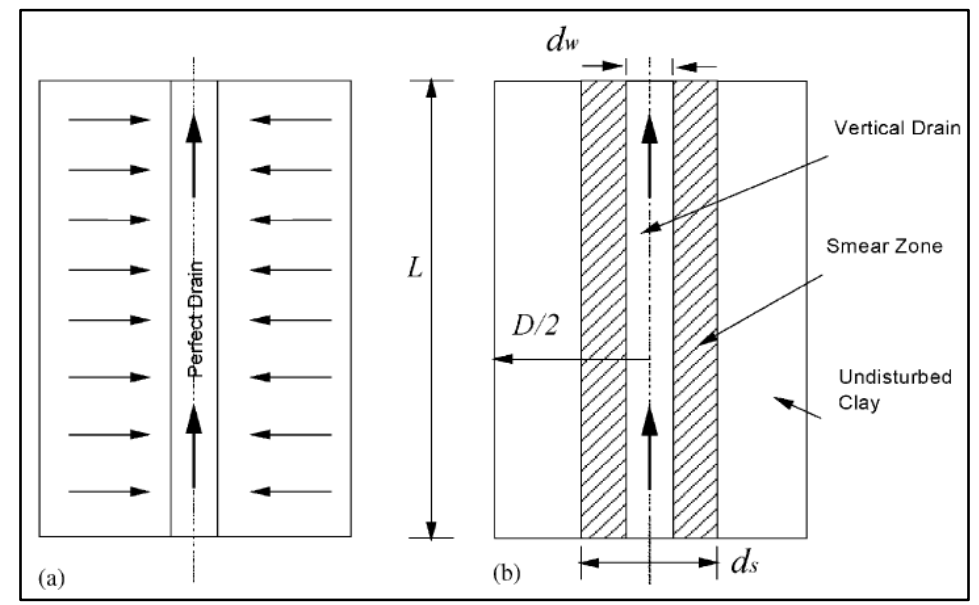

Gambar 5. Smear zone pada PVD (Sumber: Chu et al., 2004)

Penggunaan PVD tidak selalu berjalan dengan lancar. Penyebab utamanya adalah menurunnya permeabilitas PVD, sehingga kemampuan PVD untuk mendisipasi air menjadi menurun. Akibatnya, waktu yang diperlukan PVD untuk mendisipasi seluruh air di dalam lapisan tanah menjadi bertambah. Salah satu penyebab utamanya adalah tertekuknya PVD. Penelitian Bo et al. (2016), menyatakan bahwa tekukan menjadi penyebab utama berkurangnya kemampuan PVD dalam mengeluarkan air. PVD yang terlipat mengalami penurunan kemampuan mengeluarkan air hingga sebesar $75 \%$ hingga $90 \%$. Kendati demikian, besarnya penurunan dan peningkatan dipengaruhi oleh banyak faktor lain seperti jarak antar PVD, jumlah tekukan, dan ketajaman tekukan. Selain tertekuk, faktor lain yang dapat menyebabkan penurunan kinerja PVD adalah terjadinya clogging. Umumnya, tanah lunak memiliki ukuran butiran yang relatif lebih besar dibandingkan tanah lempung yang kaku. Seringkali, butiran tanah ikut terbawa oleh air ketika air bergerak menuju PVD. Akan tetapi, butiran-butiran ini tidak dapat masuk ke dalam filter membran PVD karena ukurannya yang besar. Akibatnya, butiran-butiran ini menumpuk dan menutup jalan masuk air ke dalam PVD (Basu dan Madhav, 2000). Selain itu menurut Chai dan Carter (2011), pemasangan PVD yang terlalu lama juga akan menyebabkan berkumpulnya partikel-partikel tanah di depan membran filter PVD. Disarankan PVD digunakan maksimal selama enam bulan. 


\section{METODE PENELITIAN}

Penelitian ini dilakukan dalam beberapa tahapan. Pertama, data-data tanah dari lokasi proyek, serta data PVD di lapangan dikumpulkan. Kemudian, data-data tersebut digabungkan untuk kemudian diolah. Selanjutnya, data-data tersebut dimasukkan ke dalam program beda hingga untuk dilakukan analisis. Hasil dari program berupa penurunan dan besarnya excess pore water pressure. Hasil-hasil tersebut kemudian dibandingkan dengan data lapangan, lalu digunakan untuk mengambil kesimpulan.

\section{HASIL DAN PEMBAHASAN}

Proyek gedung ini berlokasi di Bandung Selatan. Data ini tidak melampirkan data ukuran bangunan, sehingga ukuran bangunan proyek ini diambil berdasarkan ukuran yang terdapat pada aplikasi Googlearth seperti pada Gambar 6. Berdasarkan aplikasi tersebut, didapatkan ukuran bangunan kurang lebih 30×60 meter. Proyek ini memiliki data tanah berupa 1 buah titik bor dengan kedalaman 60 meter, 3 buah titik sondir dengan kedalaman 2530 meter, dan 1 buah titik CPTu dengan kedalaman 30 meter, serta hasil uji laboratorium. Berdasarkan data bor, didapatkan pula bahwa muka air tanah terdapat pada kedalaman 1 meter di bawah permukaan tanah. Rekap parameter tanah ditampilkan dalam Tabel 1. sampai Tabel 3.

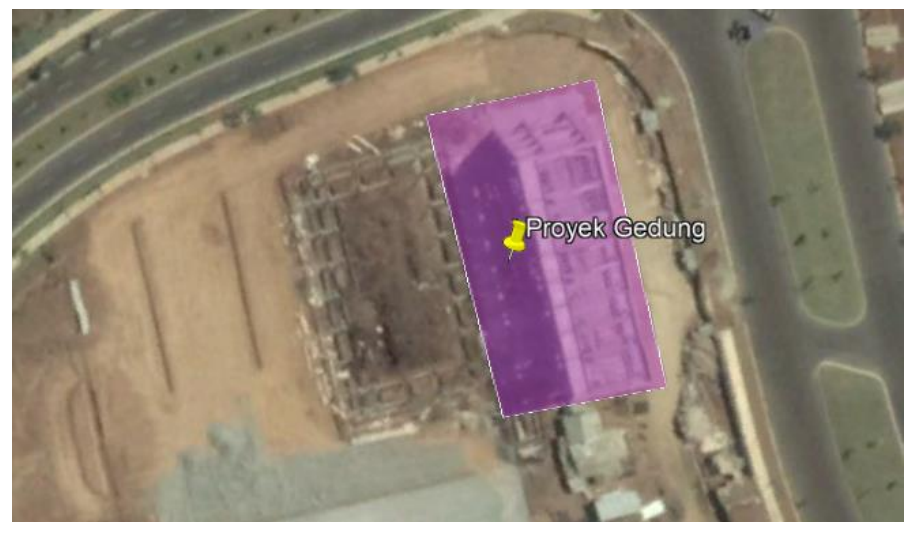

Gambar 6. Denah lokasi proyek

Tabel 1. Rekapitulasi parameter tanah (1)

\begin{tabular}{|c|c|c|c|c|c|c|c|}
\hline Lapisan & $\begin{array}{c}\text { Kedalaman } \\
(\mathbf{m})\end{array}$ & Jenis Tanah & NSPT & $\mathbf{G}_{\mathrm{s}}$ & $\mathbf{L L}$ & PL & IP \\
\hline Lapisan 1 & $0-9$ & Silty clay, soft & 3 & 2,53 & 63,74 & 32,26 & 31,74 \\
\hline Lapisan 2 & $9-21$ & Clay, soft & 4 & 2,5 & 182,35 & 143,37 & 38,98 \\
\hline Lapisan 3 & $21-25$ & Silty clay, stiff & 17 & 2,5 & 90,61 & 52,03 & 38,58 \\
\hline Lapisan 4 & $25-31$ & Silty clay, soft & 7 & 2,62 & 90,61 & 52,03 & 38,58 \\
\hline Lapisan 5 & $31-39$ & $\begin{array}{l}\text { Silty sand, } \\
\text { dense }\end{array}$ & 45 & 2,62 & 90,61 & 52,03 & 38,58 \\
\hline Lapisan 6 & $39-47$ & Silt, stiff & 22 & 2,48 & 216,98 & 166,43 & 50,55 \\
\hline Lapisan 7 & $47-51$ & Sandy silt, stiff & 33 & 2,64 & 216,98 & 166,43 & 50,55 \\
\hline Lapisan 8 & $51-60$ & $\begin{array}{l}\text { Silty sand, very } \\
\text { dense }\end{array}$ & 30 & 2,68 & 216,98 & 166,43 & 50,55 \\
\hline
\end{tabular}

Tabel 2. Rekapitulasi parameter tanah (2)

\begin{tabular}{cccccccccc}
\hline Lapisan & $\mathbf{W}(\boldsymbol{\%})$ & $\begin{array}{c}\boldsymbol{\gamma}_{\mathbf{T}} \\
\left(\mathbf{T} / \mathbf{m}^{\mathbf{3}}\right)\end{array}$ & $\begin{array}{c}\boldsymbol{\gamma}_{\mathbf{d}} \\
\left(\mathbf{T} / \mathbf{m}^{\mathbf{3}}\right)\end{array}$ & $\begin{array}{c}\boldsymbol{\gamma}_{\mathbf{s a t}} \\
\left(\mathbf{T} / \mathbf{m}^{\mathbf{3}}\right)\end{array}$ & $\mathbf{e}_{\mathbf{0}}$ & $\begin{array}{c}\mathbf{s}_{\mathbf{u}} \\
\left(\mathbf{k g} / \mathbf{c m}^{\mathbf{2}}\right)\end{array}$ & $\begin{array}{c}\boldsymbol{\emptyset} \\
\left.\mathbf{(}^{\mathbf{o}}\right)\end{array}$ & $\mathbf{O C R}$ & $\begin{array}{c}\mathbf{p}_{\mathbf{c}} \mathbf{c} \\
\left(\mathbf{T} / \mathbf{m}^{\mathbf{2}}\right)\end{array}$ \\
\hline Lapisan 1 & 66,78 & 1,67 & 1,05 & 1,635 & 1,41 & 0,303 & 4,2 & 1 & 6,749 \\
Lapisan 2 & 125,44 & 1,69 & 0,73 & 1,437 & 2,43 & 0,14 & 6,6 & 1 & 11,997 \\
Lapisan 3 & 52,03 & 1,5 & 0,93 & 1,558 & 1,69 & 0,54 & 16,5 & 2,256 & 32,098 \\
Lapisan 4 & 52,03 & 1,53 & 1,75 & 1,8 & 0,669 & 0,648 & 33,249 & 3,392 & 74,829 \\
Lapisan 5 & 52,03 & 1,53 & 1,45 & 1,9 & 0,655 & 2 & 16,5 & 5,885 & 154,769 \\
Lapisan 6 & 182,5 & 1,2 & 0,4 & 1,241 & 5,15 & 0,175 & 7,5 & 3,034 & 85,423 \\
Lapisan 7 & 182,5 & 1,2 & 1,6 & 1,9 & 0,77 & 1,9 & 7,5 & 3,783 & 120,113 \\
Lapisan 8 & 182,5 & 1,2 & 1,45 & 1,9 & 0,655 & 1,8 & 7,5 & 3,191 & 120,113 \\
\hline
\end{tabular}


Tabel 3. Rekapitulasi parameter tanah (3)

\begin{tabular}{lccccccccc}
\hline Lapisan & $\mathbf{C}_{\mathbf{c}}$ & $\mathbf{C}_{\mathbf{r}}$ & $\mathbf{C}_{\mathbf{s}}$ & $\mathbf{C}_{\boldsymbol{\alpha}}$ & $\begin{array}{c}\mathbf{c}_{\mathbf{v}} \\
\left(\mathbf{c m}^{2} / \mathbf{s}\right)\end{array}$ & $\begin{array}{c}\mathbf{c}_{\mathbf{h}} \\
\left(\mathbf{c m}^{\mathbf{2}} / \mathbf{s}\right)\end{array}$ & $\begin{array}{c}\mathbf{E}_{\mathbf{s}} \\
\left(\mathbf{k g} / \mathbf{c m}^{\mathbf{2}}\right)\end{array}$ & $\begin{array}{c}\mathbf{E}_{\mathbf{u r}} \\
\left(\mathbf{k g} / \mathbf{c m}^{\mathbf{2}}\right)\end{array}$ & $\mathbf{v}$ \\
\hline Lapisan 1 & 0,548 & 0,1548 & 0,06 & 0,033 & 0,00013 & 0,0005 & 90,783 & 272,349 & 0,183 \\
Lapisan 2 & 1,947 & 0,2 & 0,17 & 0,102 & 0,0002 & 0,0005 & 42 & 126 & 0,217 \\
Lapisan 3 & 0,383 & 0,02 & 0,07 & 0,015 & 0,00025 & 0,00102 & 162 & 486 & 0,338 \\
Lapisan 4 & 0,168 & 0,039 & 0,039 & 0,01 & 0,0002 & 0,0008 & 400 & 1200 & 0,213 \\
Lapisan 5 & 0,162 & 0,1 & 0,02 & 0,01 & 0,00013 & 0,0005 & 1600 & 4800 & 0,688 \\
Lapisan 6 & 1,642 & 0,1 & 0,09 & 0,014 & 0,00005 & 0,00002 & 140 & 510,283 & 0,4 \\
Lapisan 7 & 0,208 & 0,117 & 0,026 & 0,018 & 0,00013 & 0,0005 & 1520 & 4560 & 0,538 \\
Lapisan 8 & 0,162 & 0,1 & 0,02 & 0,005 & 0,0002 & 0,0008 & 1440 & 4320 & 0,5 \\
\hline
\end{tabular}

Selain itu, rekap properti PVD yang digunakan sesuai dengan Tabel 4. Berat jenis timbunan sebesar $1,6 \mathrm{~T} / \mathrm{m}^{3}$ dengan slope $45^{\circ}$. Tahapan pembebanan timbunan seperti pada Tabel 5.

Tabel 4. Rekapitulasi properti PVD

\begin{tabular}{lcc}
\hline \multicolumn{1}{c}{ Parameter } & Nilai & Satuan \\
\hline Diameter ekivalen & 0,05 & $\mathrm{~m}$ \\
Spasi & $1,20 \mathrm{~m}$ \\
Pola & \multicolumn{2}{c}{ segitiga } \\
Kedalaman & 27,00 & $\mathrm{~m}$ \\
Diameter efektif & 1,272 & $\mathrm{~m}$ \\
Smear zone & 0,063 & $\mathrm{~m}$ \\
$\mathrm{c}_{\mathrm{v}} / \mathrm{c}_{\mathrm{v}, \text { smear }}$ & 4,00 & \\
\hline
\end{tabular}

Tabel 5. Tahapan pembebanan timbunan

\begin{tabular}{ccc}
\hline Hari ke- & Penambahan $(\mathbf{m})$ & Tinggi Total $(\mathbf{m})$ \\
\hline 0 & $+1,6$ & 1,6 \\
45 & $+0,4$ & 2,0 \\
212 & $+0,6$ & 2,6 \\
360 & $+0,8$ & 3,4 \\
365 & $+0,3$ & 3,7 \\
370 & $+0,7$ & 4,4 \\
467 & $+0,7$ & 5,1 \\
475 & $+0,5$ & 5,6 \\
540 & $+1,9$ & 7,5 \\
545 & $+1,0$ & 8,5 \\
548 & $+0,7$ & 9,2 \\
\hline Total & 9,2 &
\end{tabular}

Hasil rekap tersebut kemudian dimasukkan ke dalam program beda hingga untuk dilakukan analisis, untuk dibandingkan dengan kondisi penurunan di lapangan. Besarnya penurunan di lapangan dinyatakan dengan settlement plate terdekat, yaitu SP38. Berdasarkan hasil analisis menggunakan program beda hingga, derajat konsolidasi 90\% pada titik SP38 dicapai pada hari ke-813,4 dengan besar penurunan total 2,43 meter. Sedangkan pada hari titik tengah timbunan, derajat konsolidasi $90 \%$ dicapai pada hari ke-819,8 dengan besar penurunan total 3,317 meter. Grafik derajat konsolidasi dicantumkan pada Gambar 7, sedangkan grafik penurunan total pada Gambar 8. Penurunan terbesar terjadi pada lapisan 1 dan lapisan 2, yaitu pada kedalaman 0 sampai 21 meter, seperti ditunjukkan Gambar 9. Adapun hasil analisis pada titik SP38 diuraikan dalam Tabel 6. 


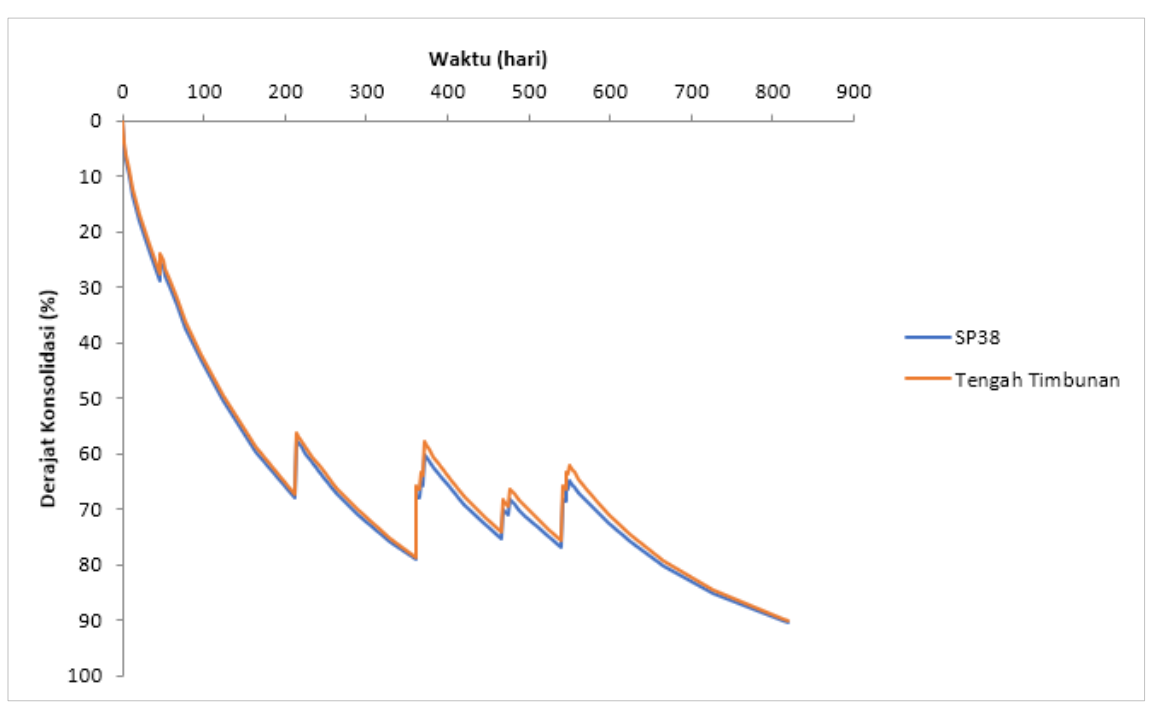

Gambar 7. Grafik hubungan derajat konsolidasi dengan waktu

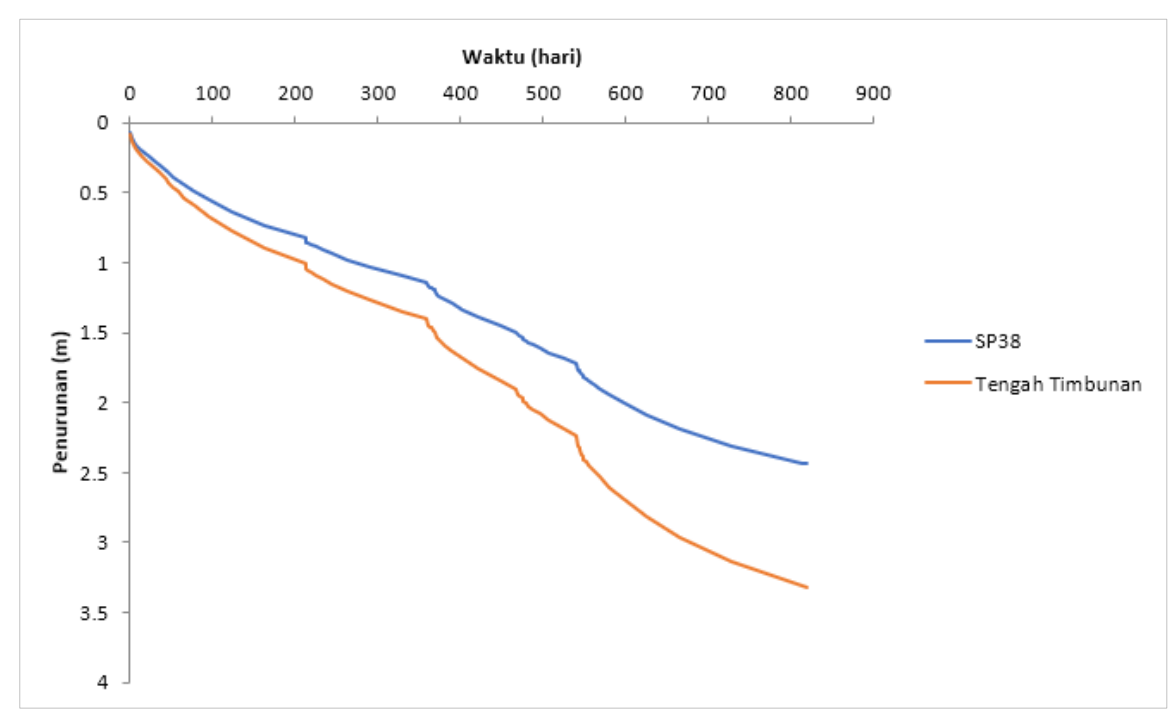

Gambar 8. Grafik hubungan penurunan total dengan waktu

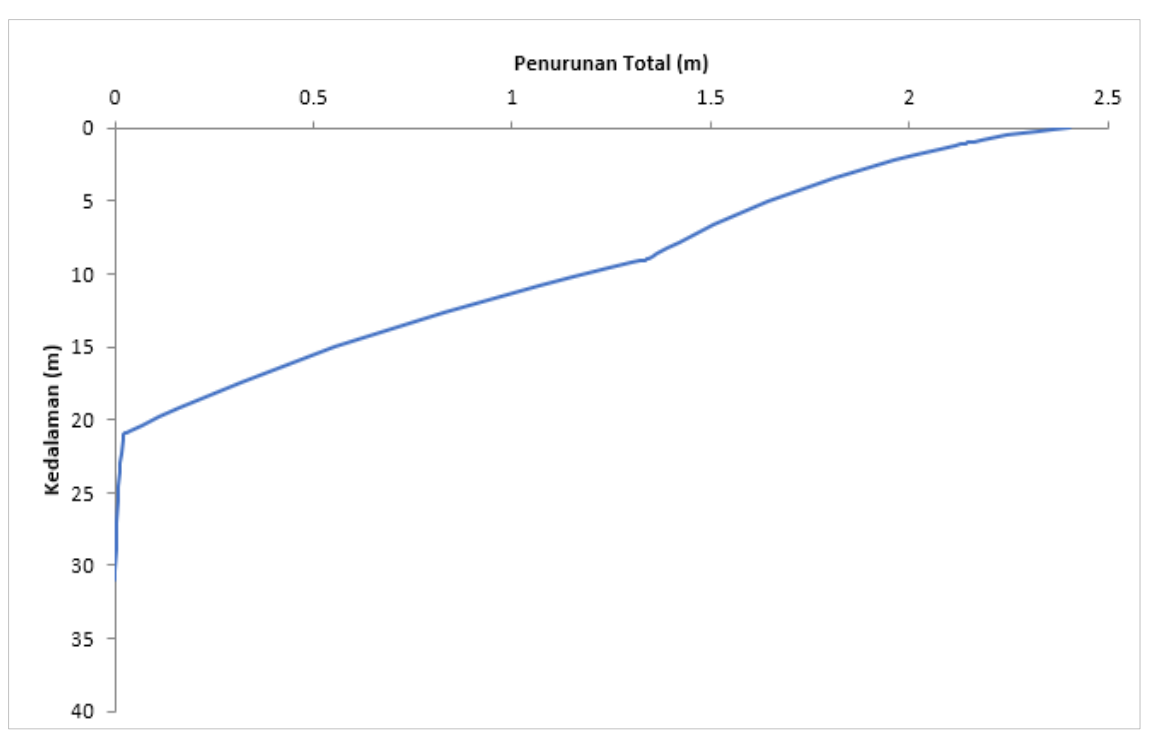

Gambar 9. Grafik hubungan penurunan dengan kedalaman pada titik SP38 
Tabel 6. Rekap hasil analisis pada titik SP38

\begin{tabular}{lcrr}
\hline \multicolumn{1}{c}{ Parameter } & \multirow{2}{*}{ Satuan } & \multicolumn{2}{c}{ Hari ke } \\
& & $\mathbf{5 4 8}$ & $\mathbf{8 1 3 , 4}$ \\
\hline Penurunan total & $\mathrm{m}$ & 1,810 & 2,430 \\
Penurunan elastis & $\mathrm{m}$ & 0,239 & 0,240 \\
Penurunan konsolidasi & $\mathrm{m}$ & 1,571 & 2,191 \\
Excess pore water pressure & $\mathrm{kPa}$ & 0,229 & 0 \\
Tekanan air pori & $\mathrm{kPa}$ & 0,229 & 0 \\
Derajat konsolidasi & $\%$ & 64,613 & 90,001 \\
Tegangan akibat beban & $\mathrm{kPa}$ & 8,805 & 8,805 \\
Tegangan prakonsolidasi & $\mathrm{kPa}$ & 8,342 & 8,876 \\
Angka pori & & 0,351 & 0,337 \\
\hline
\end{tabular}

Nilai excess pore water pressure di permukaan tanah titik SP38 pada hari ke-548 adalah sebesar 0,229 T/m². Ini berarti air yang ada di dalam pori-pori tanah belum terdisipasi seutuhnya. Air dalam pori-pori tanah masih mungkin terdisipasi dan mengakibatkan terjadinya konsolidasi lebih jauh. Air baru terdisipasi seluruhnya pada hari ke-813,4, di mana nilai excess pore water pressure pada titik SP38 telah bernilai $0 \mathrm{~T} / \mathrm{m}^{2}$. Grafik nilai excess pore water pressure ditampilkan pada Gambar 10.

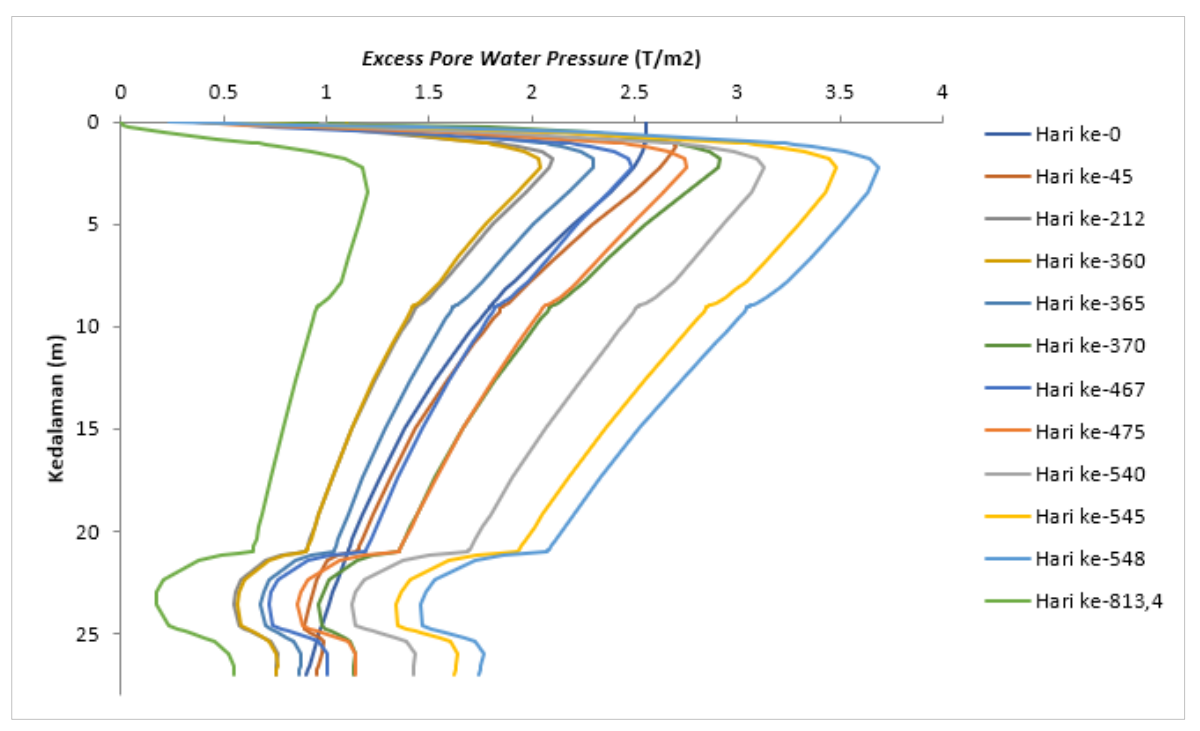

Gambar 10. Hubungan excess pore water pressure dengan kedalaman pada titik SP38

Berdasarkan hasil analisis, konsolidasi 90\% pada tengah timbunan terjadi pada hari ke-819,8 dan pada lokasi SP38 terjadi pada hari ke-813,4. Ini berarti, kondisi pada tanah akhir perbaikan di lapangan pada hari ke-548 belum terkonsolidasi seutuhnya. Akan tetapi, pelaksanaan perbaikan tanah di lapangan sudah dihentikan. Maka diduga terdapat kesalahan dalam pelaksanaan perbaikan tanah di lapangan, ataupun dalam perhitungan desain karena proses perbaikan tanah telah dihentikan ketika tanah baru mengalami penurunan sebesar 1,297 meter. Adapun nilai derajat konsolidasi 90\% dicapai pada hari ke-813,4, dengan penurunan sebesar 2,43 meter. Dengan demikian, tanah masih dapat mengalami penurunan lagi seiring dengan penambahan beban bangunan yang akan didirikan di atasnya.

Jika dibandingkan dengan besarnya penurunan yang terjadi di lapangan, maka besarnya penurunan yang didapatkan dari hasil analisis pada waktu yang sama lebih besar daripada penurunan yang terjadi di lapangan. Berdasarkan data lapangan, besar penurunan yang terjadi pada hari ke-548 di titik SP38 adalah sebesar 1,297 meter, sedangkan menurut hasil analisis adalah sebesar 1,789 meter. Perbandingan antara penurunan total di lapangan dengan hasil analisis ditunjukkan pada Gambar 11. Adanya perbedaan besar antara hasil analisis dengan kondisi di lapangan bisa terjadi karena beberapa hal. Salah satu faktor yang paling mungkin terjadi adalah tinggi timbunan yang terlalu tinggi. Tinggi timbunan (9,2 meter) melebihi tinggi kritis yang dapat ditahan oleh tanah dasar, yaitu sebesar 2,5 meter. PVD pada proyek ini juga digunakan selama 548 hari dan sangat mungkin kualitas PVD telah mengalami penurunan karena lamanya perbaikan tanah. Faktor lain yang mungkin memengaruhi adalah adanya buckling pada PVD atau clogging pada PVD. Clogging pada PVD mungkin terjadi, mengingat lapisan 
tanah lunak pada proyek ini memiliki ketebalan yang cukup besar, sehingga mungkin banyak butiran tanah yang menghambat air masuk melalui filter membran PVD.

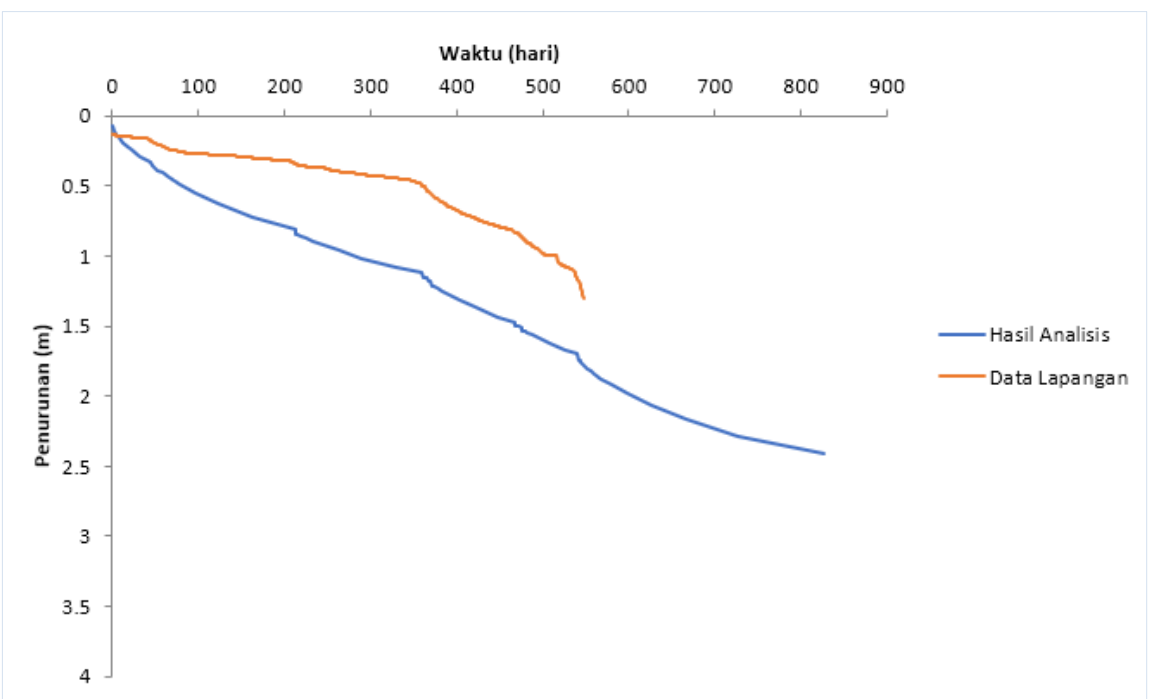

Gambar 11. Perbandingan penurunan total di lapangan dengan hasil analisis di titik SP38

Adanya clogging menyebabkan menurunnya kemampuan PVD dalam mendisipasikan air tanah akibat menurunnya permeabilitas PVD. Analisis kemudian dilakukan terhadap berbagai nilai $\mathrm{c}_{\mathrm{h}}$, yang kemudian dibandingkan dengan hasil terjadi di lapangan seperti pada Gambar 12.

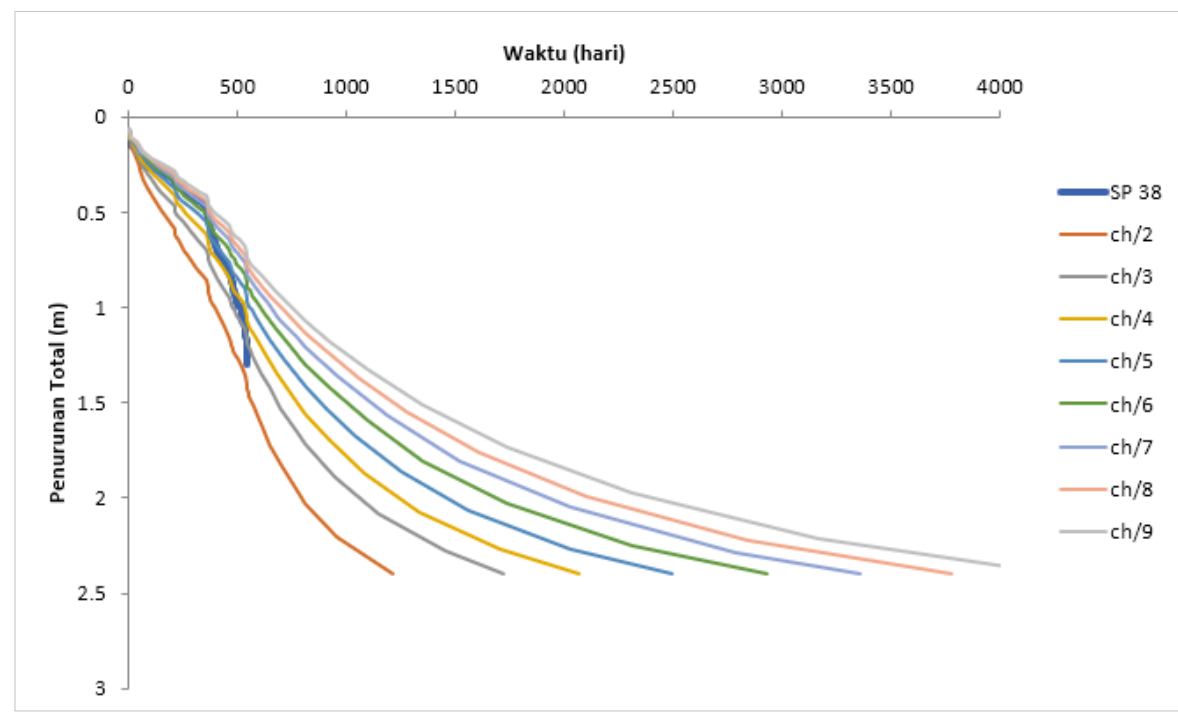

Gambar 12. Hubungan penurunan total dengan kedalaman akibat berbagai nilai $\mathrm{c}_{\mathrm{h}}$

Berdasarkan Gambar 12, diketahui bahwa besarnya penurunan yang terjadi di lapangan pada 365 hari pertama menyerupai perhitungan dengan menggunakan nilai $\mathrm{c}_{\mathrm{h}}$ sebesar $1 / 6$ kali nilai $\mathrm{c}_{\mathrm{h}}$ awal. Adapun ketika memasuki hari ke-365, gradien penurunan berubah menjadi lebih curam dan tidak sesuai dengan hasil analisis. Ada beberapa faktor yang mungkin menyebabkan terjadinya fenomena membesarnya nilai ini. Salah satunya adalah kemungkinan dimulainya proses konsolidasi sekunder. Selain itu, mungkin juga ada sebuah lapisan tanah, yang tidak tercatat dalam hasil sondir dan boring, yang berubah sifatnya menjadi normally consolidated setelah penambahan beban pada hari ke-365.

\section{KESIMPULAN DAN SARAN}

Berdasarkan hasil analisis yang telah dilakukan, dapat disimpulkan beberapa hal sebagai berikut. 
1. Proyek gedung di Bandung Selatan ini terletak pada lokasi dengan lapisan tanah yang lunak di bagian atasnya. Terbukti berdasarkan rekap parameter, tanah pada kedalaman 0 sampai 21 meter termasuk tanah lunak.

2. Berdasarkan hasil analisis program beda hingga, besar penurunan pada titik SP38 untuk mencapai nilai konsolidasi 90\% adalah sebesar 2,43 meter. Besarnya konsolidasi 90\% ini dapat dicapai dalam 813,4 hari, jika menggunakan tahapan pembebanan seperti yang dilakukan di lapangan.

3. Berdasarkan hasil analisis program beda hingga, nilai excess pore water pressure pada permukaan tanah titik SP38 ketika perbaikan tanah dihentikan atau hari ke-548 adalah sebesar 0,229 kPa.

4. Proses perbaikan tanah dihentikan ketika penurunan di lapangan sebesar 1,297 meter. Nilai ini masih belum mencapai besar penurunan untuk konsolidasi 90\%, di mana besarnya derajat konsolidasi yang dicapai adalah sebesar 53,37\%.

5. Besarnya penurunan tanah di lapangan mengalami penyimpangan dari besarnya penurunan hasil analisis program beda hingga dan terjadi akibat beberapa kemungkinan. Sliding dan proses perbaikan tanah yang terlalu lama diduga menjadi faktor yang kemungkinan besar menyebabkan terjadinya hal ini. Faktor lain yang mungkin memengaruhi adalah clogging atau buckling pada PVD.

6. Tanah mengalami penurunan yang drastis setelah memasuki hari ke-365. Penulis menduga hal ini terjadi karena beberapa kemungkinan, seperti adanya lapisan tanah yang berubah menjadi normally consoldiated akibat penambahan beban pada tahapan tersebut, atau dimulainya konsolidasi sekunder.

Adapun saran untuk pengembangan penelitian ini lebih lanjut adalah sebagai berikut.

1. Analisis selanjutnya dapat melakukan pengecekan terhadap kapasitas PVD, serta pelaksanaan instalasinya di lapangan, seperti jarak dan kedalaman.

2. Dampak clogging dapat diperhitungkan lebih lanjut dalam analisis selanjutnya.

3. Untuk analisis selanjutnya, disarankan memperhitungkan konsolidasi sekunder.

\section{DAFTAR PUSTAKA}

Basu, Dipanjan dan Madhira Madav. "Effect of Prefabricated Vertical Drain Clogging on the Rate of Consolidation: A Numerical Study." Geosynthetics International 7.3 (2000): 189-215.

Bo, Myint Win, et al. "Laboratory Measurements of Factors Affecting Discharge Capacity of Prefabriacted Vertical Drain Materials." Soils and Foundations 56.1 (2016): 129-137.

Boussinesq, Joseph. Application des Potentials à L'Etude de L'Equilibre et du Mouvement des Solides Elastiques. Paris: Gauthier-Villars, 1883.

Budhu, Muni. Soil Mechanics Fundamentals. Chichester: John Wiley \& Sons, Ltd, 2015.

Chai, Jinchun dan John P. Carter. Deformation Analysis in Soft Ground Improvement. Dordrecht: Springer Science+Business Media B.V., 2011.

Chu, J., M. W. Bo dan V. Choa. "Practical Considerations for Using Vertical Drains in Soil Improvement Projects." Geotextiles and Geomembranes 22 (2004): 101-117.

Das, Braja M. Advanced Soil Mechanics Fifth Edition. Boca Raton: CRC Press, 2019.

Das, Braja M. Principles of Foundation Engineering, 8th Edition. Boston: Cengage Learning, 2014.

Das, Braja M. Principles of Geotechnical Engineering, 7th Edition. Stanford: Cengage Learning, 2013.

Gunawan, Tomy, Alfred Jonathan Susilo dan Ali Iskandar. "Analisis Penurunan pada Timbunan dengan Prefabricated Vertical Drain (PVD) Menggunakan Data Hasil Uji CPTu.” Jurnal Mitra Teknik Sipil 3.1 (2020): 69-80.

Han, Jie. Principles and Practices of Ground Improvement. Hoboken: John Wiley \& Sons, Inc., 2015.

Kaliakin, Victor. Soil Mechanics: Calculations, Principles, and Methods. Kidlington: Butterworth-Heinemann, 2017.

Prativi, Ayu, Septiana Widi Astuti dan Ahmad Ependi. “Aplikasi Prefabricated Vertical Drain (PVD) untuk Stabilisasi Tanah Dasar pada Proyek Pembangunan Jalur Ganda Kereta Api di KM 437+300 sampai KM 438+500 Gombong, Kebumen.” Jurnal Perkeretaapian Indonesia 3.1 (2019): 1-5.

Sakleshpur, V. A., M. Prezzi dan R. Salgado. "Ground Engineering Using Prefabricated Vertical Drains: A Review." Geotechnical Eningeering Journal of the SEAGS and AGSSEA 49.1 (2018): 45-64.

Tran-Nguyen, H.-H. dan T. B. Edil. "The Characteristics of PVD Smear Zone.” Geo-Frontiers 211 (2011): 748757.

Wilson dan Alfred Jonathan Susilo. "Perbandingan Penurunan Konsolidasi antara Tanah yang Belum Diperbaiki serta yang Diperbaiki dengan Preloading dan Pemancangan Keliling.” Jurnal Mitra Teknik Sipil 1.2 (2018): 151-160. 